\title{
Situación actual del régimen local en Extremadura
}

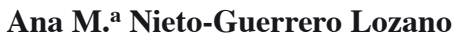 \\ Profesora Titular de Derecho Administrativo de la Universidad de Extremadura
}

Sumario: I. EL ESTADO DE LA CUESTIÓN RELATIVA A LA LEY DE ENTIDADES LOCALES. - II. RECIENTES NORMAS AUTONÓMICAS SOBRE EL RÉGIMEN LOCAL Y ALGUNAS REFLEXIONES SOBRE LAS MISMAS. 1. Decreto 31/2007, de 20 de febrero, por el que se regula la asignación, configuración y gestión de la Sección Condicionada del Fondo Regional de Cooperación Municipal (DOE, núm. 24, de 27 de febrero de 2007). 2. Decreto 104/2006, de 30 de mayo, por el que se establecen las bases reguladoras para la concesión de ayudas a los grupos de acción local en la ejecución de los programas de desarrollo rural LEADER+ y PRODER II (DOE, núm. 66, de 6 de junio de 2006). 3. Decreto 309/2007, de 15 de octubre, por el que se regula el procedimiento de rehabilitación, modificación o adaptación de escudos, banderas y otros símbolos de las Entidades Locales de Extremadura (DOE, núm. 121, de 18 de octubre de 2007).

\section{EL ESTADO DE LA CUESTIÓN RELATIVA A LA LEY DE ENTIDADES LOCALES}

Hablar de la situación actual del régimen local en Extremadura nos obliga a ubicar esta materia en el contexto normativo de nuestra Comunidad Autónoma (en adelante, CA) y, en definitiva, en el contexto normativo que se desprende de la Constitución Española (en adelante, CE) y de nuestro Estatuto de Autonomía (en adelante, EA).

Para ello diremos que aunque, realmente, la materia relativa al régimen local o a la Administración Local no aparece, como competencia propia del Estado o de la CA, en los listados de materias previstos en los arts. 148 y 149 CE, sin embargo, es cierto que referencias, más o menos explícitas, a la misma, se contienen en los arts. 148.1.2 y 149.1.18 $\mathrm{CE}^{1}$.

Precisamente, en virtud de las posibilidades que se desprendían de estos preceptos, la CA Extremeña asumió, en el art. 8.1 de su originario EA, de 1983, competencias de desarrollo legislativo y ejecución en la materia, en el marco de la legislación básica del Estado, en los siguientes términos: "Régimen local en la forma prevista en el artículo 148.1.2 de la Constitución y, en especial, la alteración de los términos y denominaciones de los municipios comprendidos en su territorio, así como la creación de organizaciones de ámbito inferior y supe-

\footnotetext{
1 Un análisis de lo que supone la delimitación constitucional de competencias sobre el régimen local, en mi trabajo: «La Administración Local en la Comunidad Autónoma de Extremadura», en El Derecho de Extremadura. Estudios sobre el Estatuto y el Derecho de la Comunidad Autónoma de Extremadura, Asamblea de Extremadura, Badajoz, 2005, págs. 239-241.
} 
rior a los mismos, en los términos establecidos en el artículo 2.2 de este Estatuto $»^{2}$. A su vez, en la medida en que se asumían competencias sobre régimen local en la forma prevista en el art. 148.1.2 CE, las competencias que, efectivamente, pasaban a ser propias eran las relativas a: «Las alteraciones de los términos municipales, comprendidos en su territorio y, en general, las funciones que correspondan a la Administración del Estado sobre las Corporaciones Locales y cuya transferencia autorice la legislación sobre Régimen Local».

Pero además, de lo previsto en el art. 8.1 EA también hay que traer a colación, ahora, la regulación que se contiene en el art. 16, en tanto que en éste se regulan las relaciones que deberían establecerse entre las Entidades Locales (en adelante, EL) y la CA.

Bien, pues a la vista de la regulación contenida en estos y otros preceptos, podríamos destacar, en estos momentos $^{3}$, que nuestra CA es la única que, al día de hoy, aún no ha ampliado, en modo alguno, sus competencias sobre el régimen local ${ }^{4}$ y lo que aún puede ser más significativo, aún no ha aprobado ninguna Ley Autonómica sobre la materia ${ }^{5}$. Y ello a pesar de que la regulación de esta materia se ha erigido en uno de los objetivos legislativos prioritarios de las tres últimas campañas electorales del partido gobernante. Y de que, en los últimos tiempos, se viene reclamando, incesantemente, al Gobierno extremeño, su presentación y aprobación. Reclamación que ya se hizo en 1999, por la Federación Extremeña de Municipios y Provincias y que se viene haciendo, cíclicamente, por el principal partido de la oposición 6 , el Partido Popular; siendo la última, de 28 de septiembre de 2007, por la cual se formula una pregunta para respuesta oral en el Pleno, relativa a: ¿Cuándo tiene previsto la Junta de Extremadura traer a la Asamblea la tan demandada y necesaria Ley de Entidades Locales de Extremadura??

\footnotetext{
2 Competencias originariamente asumidas que no han sido objeto de ampliación en las sucesivas reformas estatutarias que se han llevado a cabo en los años 1991, 1994 y 1999. A diferencia de lo que ha ocurrido en el resto de CCAA en las que, básicamente, entre los años 1996 a 1999, se han reformado sus EEAA para, entre otras cosas, ampliar sus competencias en esta materia; con independencia de que alguna de estas CCAA no haya aprobado, tampoco, la correspondiente Ley Local.

3 Y ello sin perjuicio de que, ya, hayamos hecho un análisis más exhaustivo de este tema, en el trabajo anteriormente referido, «La Administración...», cit., págs. 237-280.

4 Queda por ver, no obstante, si la próxima reforma de nuestro EA abordará, finalmente, la ampliación referida.

5 Sin olvidar, ahora, la escasamente, por no decir nada, aplicada, Ley 5/1990, de 30 de noviembre, de relaciones entre las Diputaciones Provinciales y la Comunidad Autónoma.

6 En la presente Legislatura, único partido de oposición.

7 Boletín Oficial de la Asamblea de Extremadura, VII Legislatura, núm. 18, de 9 de octubre de 2007, pág. 9. Repárese en que la urgencia a la hora de contar con una ley local extremeña cada vez se ha hecho más apremiante, como lo demuestra el hecho de que cuando en 2005 o 2006, se preguntaba por la misma cuestión, se hacía en unos términos, podríamos decir «más fríos», se preguntaba, genéricamente, por el Proyecto de Ley de Entidades Locales (al respecto, véanse los Diarios de Sesiones de la Asamblea de Extremadura, VI Legislatura, núm. 55-P, sesión plenaria n. ${ }^{\circ}$ 49, de 20 de octubre de 2005 y el núm. 79-P, sesión plenaria n. ${ }^{\circ}$ 71, de 9 de noviembre de 2006). Mientras que en 2007, ya no se habla ni siquiera de proyecto, sino directamente de la «tan demandada y necesaria Ley de Entidades Locales» (Diario de Sesiones de la Asamblea de Extremadura, VII Legislatura, núm. 8-P, sesión plenaria n. ${ }^{\circ}$ 6, de 11 de octubre de 2007).
} 


\section{SITUACIÓN ACTUAL DEL RÉGIMEN LOCAL EN EXTREMADURA}

Luego, por tanto, la situación normativa, o mejor, legislativa, del régimen local, a finales de 2007, es la misma que venimos arrastrando desde 1983, es decir, tener asumidas competencias, en la materia, mínimamente, ${ }^{8}$ y no haber desarrollado legislativamente, ni siquiera, esas mínimas competencias.

Pero una vez puesta de manifiesto esta realidad, consideramos oportuno destacar y, al mismo tiempo, aclarar también ${ }^{9}$, cuáles son los aspectos de la genérica materia «régimen local» sobre los que giran nuestras competencias estatutarias, efectivamente asumidas. Centrándonos, en especial, en lo que se refiere a la asunción de competencias legislativas, y evitando pronunciarnos, en estos momentos, sobre las meramente ejecutivas o administrativas.

Entendemos, así, que dichas competencias legislativas, en función de lo previsto, en los referidos arts. 8.1 y 16 de nuestro EA, deben girar, en todo caso, sobre: la creación y supresión de municipios y sobre cualquier tipo de alteración (segregaciones) del territorio de los mismos; sus denominaciones (símbolos, banderas y distinciones); la creación de organizaciones de ámbito inferior (EELL Inframunicipales) y superior a los mismos (lo que llama, irremediablemente, al tema del asociacionismo, en el nivel local ${ }^{10}$ ) y de forma más genérica, sobre los instrumentos de relación y cooperación interadministrativa.

Por otra parte, estos han sido los aspectos que, básicamente y como mínimo, han venido regulando la práctica totalidad de las CCAA hasta que, en los últimos tiempos ${ }^{11}$, la ampliación de competencias en la materia, les ha permitido, a algunas de ellas, una regulación más amplia.

Entre las primeras, es decir, entre aquellas CCAA que tenían un nivel de competencias, entonces, igual al que tiene ahora la CA de Extremadura y, como mínimo, regulando los aspectos, anteriormente, referidos, destacamos las siguientes leyes: Ley Murciana 6/1988, de 25 de agosto, de Régimen Local; Ley Castellano-Manchega 3/1991, de 14 de marzo, de Entidades Locales; Ley Andaluza 7/1993, de 22 de julio, de Demarcación Territorial, Ley Riojana, 3/1993, de 22 de septiembre, de Régimen Local ${ }^{12}$ y Ley Castellano Leonesa 1/1998, de 4 de junio, de Régimen Local.

Aunque debemos poner de manifiesto que, a nuestro juicio, y en función del nivel de competencias asumido, entonces, por estas CCAA, la denominación más correcta de estas leyes era la propia de la Ley Manchega, mientras que la

\footnotetext{
8 Lo que tiene como consecuencia, impedir a nuestra CA regular el régimen jurídico completo de los EELL.

9 Pues hemos podido comprobar, en algún momento, que existen ciertas dudas o incertidumbres sobre el tema.

10 Piénsese, especialmente, en las Mancomunidades de Municipios o en los Consorcios.

11 Entre los años 1996 y 1999, como hemos destacado.

12 Ley ya derogada por la vigente Ley 1/2003, de 3 de marzo, de Administración Local.
} 
que se atribuyó por las CCAA Murciana, Riojana y Castellano-Leonesa resulta, entendemos, errónea, pues cuando se aprobaron estas leyes, dichas CCAA no tenían asumida la competencia unitaria sobre el régimen local, sino sólo sobre algunos aspectos de dicho régimen que fueron, precisamente, los que se regularon y no, el completo régimen local. Eran, por tanto, aspectos concretos del régimen local los que se regulaban por estas leyes autonómicas. Aspectos concretos que, serían los únicos que, al día de hoy, podrían ser objeto de regulación, en Extremadura.

A su vez, entre las segundas, es decir, entre las CCAA que han asumido competencias, originariamente o por ampliación, globalmente sobre el régimen local ${ }^{13}$, y que han aprobado sus correspondientes Leyes, destacaríamos: Cataluña, Navarra, Galicia, Aragón, La Rioja, Madrid y, recientemente, las Islas Baleares ${ }^{14}$.

Aunque volviendo, de nuevo, a la situación legislativa de la materia, en la CA Extremeña, debemos insistir en la idea de que el hecho de que aún no se haya aprobado ninguna Ley autonómica, es un tema candente y de permanente actualidad. Como lo prueba el hecho de que, en los últimos tiempos, dicha ausencia esté «pidiendo a gritos», ser suplida.

Como hemos destacado, recientemente, el Partido Popular de Extremadura ha presentado, y se ha debatido, en la sesión plenaria de la Asamblea de Extremadura, núm. 6, de 11 de octubre de 2007, una pregunta relativa a la «tan demandada y necesaria Ley de Entidades Locales», si bien es cierto que, como mínimo, en los dos años anteriores, ha venido haciendo lo mismo, aunque quizás con menos contundencia, en relación con la que lo ha hecho en 2007.

Incidiremos, no obstante, porque nos parece especialmente significativo de la confusión reinante en la materia, en el debate que se produjo, a propósito de la pregunta formulada en $2006^{15}$, pues, a la vista de las intervenciones que se produjeron en aquella sesión plenaria, tanto por parte de los representantes del PP, como del PSOE y de Izquierda Unida-Socialistas Independientes de Extremadura, parecía desprenderse que ni unos, ni otros, sabían, a ciencia cierta, que es lo que debía «cocerse en la olla de la ley local extremeña». Y pretendían añadir a la misma, ingredientes que, a nuestro juicio, en modo alguno, al menos, hoy por hoy, pueden ser objeto de regulación en una Ley Extremeña de Entidades Locales. Se reclamaba así, por ejemplo, por parte del representante popular ${ }^{16}$, aunque valga decir que sin ningún tipo de orden ni concierto, una

13 Lo que les permite, por tanto, una regulación más completa y exhaustiva de dicho régimen y, por tanto, calificarse, más propiamente, como Leyes de Administración o Régimen Local.

14 Ex Ley 20/2006, de 15 de diciembre, municipal y de régimen local (BOE, núm. 26, de 30 de enero de 2007)

15 Diario de Sesiones de la sesión plenaria n. ${ }^{\circ}$ 71, celebrada en Mérida, el jueves 9 de noviembre de 2006.

16 Diario de Sesiones de la Asamblea de Extremadura, VI Legislatura, núm. 79-P, pág. 3997 y ss. 


\section{SITUACIÓN ACTUAL DEL RÉGIMEN LOCAL EN EXTREMADURA}

Ley Local extremeña que regulase, entre otras cosas: «...el régimen de gestión de los servicios públicos y su financiación, la contratación, las haciendas locales, la gestión presupuestaria y el endeudamiento de los Entes Locales, el personal al servicio de la misma...o la aplicación del régimen de grandes ciudades. Se decía, igualmente: «debemos delimitar las competencias de las entidades locales,... dotarlas de la financiación adecuada,... resolver la prestación y financiación de los servicios impropiamente prestados por los entes locales...».

Pero, a la vista de los contenidos normativos reivindicados, nosotros creemos que además de hacerse unas reivindicaciones demasiado pretenciosas para una mera Ley autonómica de Entidades Locales, no se tiene nada claro cuáles son los objetivos que, con dicha Ley, se pueden perseguir y, en consecuencia, obtener, en Extremadura.

Nos estamos refiriendo, de nuevo, a un aparente desconocimiento o, al menos, un gran desconcierto, acerca de cuáles pueden ser los aspectos que, en función de las competencias estatutarias, actualmente asumidas, pueden ser objeto de regulación, en dicha Ley.

Aunque no podemos olvidar, ahora, que este tema, relativo al contenido normativo de la futura ley local autonómica, tampoco parecía tenerlo demasiado claro, el representante del partido del Gobierno extremeño ${ }^{17}$; pues, en caso contrario, es decir, de haberlo tenido claro, debería haber llegado a la conclusión de que no procedía, entre otras cosas, vincular y aplazar la aprobación de la Ley extremeña local a la aprobación de la reforma de la Ley local básica.

No procedía, ni procede porque, a nuestro juicio, dicha conexión no es, estrictamente, necesaria. O mejor, no es necesaria, en sentido estricto, si nuestra CA respeta en su Ley local autonómica, como por otra parte debe de hacer, su propio ámbito material de competencias, circunscrito, como decimos, a los aspectos anteriormente señalados. Pues si así lo hace ${ }^{18}$, se encontrará con que, precisamente, los aspectos, sobre los que, hoy por hoy, puede legislar, son tan claramente autonómicos que, ni la vigente Ley básica estatal, ni la futura (al menos, en los términos que se desprenden del contenido del Libro Blanco para la reforma del Gobierno Local, que editó el MAP en julio de 2005), los regula y cuando, por el contrario, los regula, lo hace con un carácter tan somero, que está llamando, irremediablemente, «a escena», al legislador autonómico de desarrollo.

Parece, precisamente, que este alto grado de confusión acerca del contenido normativo de la Ley autonómica, ha contribuido, en gran medida, a evitar «su

17 Como se desprende de su intervención, en la sesión plenaria de noviembre de 2006 (Diario de Sesiones de la Asamblea de Extremadura, VI Legislatura, núm. 79-P, pág. 3998 y 3999).

18 Insistimos, como debe de hacer. 
definitivo despegue». Y, sin embargo, no podemos dejar de señalar que tanto ahora, como hace ya unos años, su aprobación hubiera sido y es, muy conveniente, pues se hace necesario contar con un mínimo común denominador normativo autonómico que asegure la tan demandada «certeza del derecho», al menos, sobre algunas cuestiones locales de especial incidencia en Extremadura y que deberían girar, en todo caso, sobre los aspectos que hemos destacado, anteriormente.

Por el contrario, las pretensiones normativas que excedan de dichos contenidos normativos, a nuestro juicio, serán especialmente llamativas, a la hora de ser reivindicadas, pero, a la vez, imposibles de materializar, en virtud de nuestro actual nivel de competencias, sobre la materia. Además, porqué no decirlo, constituirá una manifestación más, de la demagogia ${ }^{19}$ que domina la política, en general, y también, porque no conseguimos librarnos de ella, la política extremeña.

Y ello con independencia de que, por otra parte, la ampliación competencial en la materia, que permitiera una regulación más extensa sobre el régimen local, también sería posible, si hubiese voluntad política para reformar el EA, respecto de esta cuestión.

Reforma que como viene declarando, desde principios de 2007, el entonces candidato del PSOE a la Junta de Extremadura, en las elecciones autonómicas de mayo de 2007 y ahora Presidente Autonómico, Guillermo Fernández Vara, será irremediable que se produzca, en los próximos años, como consecuencia del fervor imperante de reformas estatutarias en el que nos hallamos inmersos. Fruto, sin duda, de la primera y reciente reforma de alcance de un EA, cual ha

19 Demagogia, como la que se desprendía de la intervención del representante popular, al afirmar, en 2006, entre otras cosas, que lo que ellos pedían de la ley que venían reclamando era: «...mejorar el nivel de vida de los ciudadanos, una ley para que los ayuntamientos extremeños puedan atender a las demandas de esos ciudadanos, con unas normas claras, iguales para todos, y con la dotación económica adecuada a las competencias que se presten, y caminar en la senda de la segunda descentralización». Insistiendo en la idea de que, con esta ley, ellos pedían cuatro cosas: «... impulsar la segunda descentralización, aumentar y mejorar la financiación local, resolver la prestación y financiación de los servicios impropiamente prestados por las entidades locales y regular la función pública local.» (Diario de Sesiones..., cit., pág. 4001).

No obstante, a la vista de lo que se reivindicaba y de las posibilidades reales de alcanzar lo reivindicado, nos vemos obligados a formular la siguiente cuestión: ¿Realmente, el representante popular se creía que estos objetivos se pueden obtener con la concreta Ley que estaba reivindicando?. Pues si era así, si realmente se lo creía, definitivamente, creemos que puede afirmarse que los políticos no están en la realidad y, lo que es aún peor, no están en la realidad constitucional, ni estatutaria. Pero si, por el contrario, de lo que estaban hablando era de competencia legislativa estatal, en sede autonómica, a modo de totum revolutum, creemos que poco se está valorando la Asamblea legislativa extremeña; dado que la misión de la misma es albergar el debate y aprobación de la legislación autonómica, no de la legislación estatal. Pues ésta última ya tiene su propia sede. Mejor hubiera sido, por el contrario, a nuestro juicio, haberse centrado, en aspectos locales de especial importancia para Extremadura y realmente asumibles, por nuestra CA, como precisamente, traía a colación el representante popular, al final de su intervención (pág. 4001), cuando aludía a la importancia que tienen, en nuestra Región, las Mancomunidades de Municipios y a la nula regulación de la materia. Esto sí, entre otras cosas ajustadas a la realidad local extremeña, que hubiera permitido un debate político provechoso, en sede autonómica. El resto, no es más que pura demagogia. 


\section{SITUACIÓN ACTUAL DEL RÉGIMEN LOCAL EN EXTREMADURA}

sido el EA de Cataluña y que, precisamente, se ha producido a principios de 2006. Sería, por tanto, a nuestro juicio, el régimen local una de las materias que tendría que ser objeto de ampliación, con la siguiente reforma estatutaria.

Pero, insistimos, ni la futura reforma de la Ley básica local, ni de nuestro EA, deberían servir, ni haber servido, de excusa para no aprobar una Ley autonómica en la materia. Concretamente, respecto de aquellos aspectos que tenemos asumidos, desde la aprobación originaria de nuestro EA, en 1983. Ni justifica que durante todos estos años, los operadores jurídicos extremeños no hayan podido disponer de un instrumento legislativo claro que, al menos, para dichos aspectos, les hubiera ayudado en la vida local diaria. Especialmente, si tenemos en cuenta que 2005, fue el plazo (parecía que ineludible), que se dio el anterior Presidente Autonómico para solventar dicha omisión. Lo cierto es, en cambio, que ha pasado 2005, 2006 y 2007 y la situación normativa en la materia, desgraciadamente, no se ha modificado. Y ello a pesar de que como prueba el Diario Oficial de Extremadura y el propio día a día de la gestión administrativa local, haber dispuesto de una regulación autonómica de los aspectos que hemos referido, habría resultado especialmente conveniente y clarificadora.

Especialmente conveniente resultaría ser, por tanto, la aprobación de una Ley que contuviera, entre otros aspectos y, en los términos que se desprenden, como decimos, de los arts. 8.1 y 16 de nuestro EA, la regulación relativa a:

1) la precisión de las EELL extremeñas (destacando, especialmente, por la importancia que tienen en nuestro territorio, las Entidades Locales Menores y las Mancomunidades de Municipios);

2) los temas relativos a la demarcación territorial: creación, supresión, segregación, procedimiento para ello, repercusiones de la alteración, procedimientos de deslinde,...;

3) denominación, capitalidad y procedimientos para la rehabilitación, modificación o adaptación de escudos, banderas y otros símbolos de las EELL (elevando así el rango de la actual normativa que regula estas cuestiones, cual es el estrenado Decreto 309/2007, de 15 de octubre, que ha venido a derogar al anterior Decreto 63/2001, de 2 de mayo, de regulación de los símbolos, tratamientos y honores de las EELL);

4) una regulación exhaustiva de las Entidades Locales Menores, respecto de las cuales la CA tiene amplias competencias, dejando a salvo, no obstante, los aspectos básicos contenidos en el art. 45.2 LRBRL, aunque regulando sobre cuestiones tales como: potestades, competencias, procedimiento de creación, ámbito territorial de actuación, órganos de gobierno y administración, recursos económicos, supuestos y procedimientos de modificación y supresión,...); 
5) una regulación profunda de las Mancomunidades de Municipios, cuya proliferación en nuestra $\mathrm{CA}$, como consecuencia del vigente inframunicipalismo y de la necesidad de ámbitos territoriales más amplios para conseguir una mayor eficacia y eficiencia administrativas, constituye una constante realidad, como expresión del asociacionismo municipal voluntario, ex art. 44.1 LRBRL y respecto de las que habría que regular cuestiones relativas a su: capacidad jurídica, competencias, potestades, procedimiento de aprobación y modificación de sus Estatutos, órganos de gobierno y administración, normas sobre organización y funcionamiento, recursos materiales y personales, mancomunidades integrales, agrupación, disolución.....);

6) regulación de algunos instrumentos de relación interadministrativa, contemplados actualmente en el EA (transferencia, delegación,....);

7) la regulación de algunas de las más significativas técnicas de cooperación jurídica, económica y técnica, que permitieran ofrecer diversas posibilidades para encontrar aquella solución que satisficiera, de la mejor manera posible, la gestión de los asuntos públicos que las EELL tiene encomendadas, tales como: Consejo Extremeño de Administración Local; Fondo Regional de Cooperación Local: su finalidad, EELL beneficiarios, carácter incondicionado de su asignación ${ }^{20}$, criterios para su distribución; Consorcios, especialmente significativos cuando en la organización supramunicipal, resulte necesaria la intervención de las Provincias: entidades consorciadas, naturaleza jurídica, fines, régimen jurídico, potestades, prerrogativas, procedimiento de creación y extinción cuando se integra, exclusivamente, por EELL, sus Estatutos, medios materiales y personales,...; Sociedades Mercantiles; Convenios de Cooperación y Coordinación (planes sectoriales, unión de planes autonómicos y provinciales,....).

Sin duda, la regulación de estas cuestiones, como sería, por ejemplo, lo relativo a las Mancomunidades de Municipios o, a los Consorcios, resultaría de especial interés y tendría un claro carácter de mínimos en una CA, como la extremeña, caracterizada por una amplia extensión territorial y por un endémico «inframunicipalismo» que dificulta, enormemente, el ejercicio de las competencias y la prestación de los servicios locales y obliga, permanentemente, al imprescindible «asociacionismo local». Aunque, al mismo tiempo y, en el otro extremo del «vector local», también podría satisfacerse, con la regulación que se propone, las aspiraciones de ciertas comunidades vecinales que sienten la

\footnotetext{
20 Tema éste que también viene siendo objeto de ciertos desvelos por parte de los políticos autonómicos, como lo prueba la pregunta que, también por el único partido de oposición extremeño, se ha formulado, recientemente, relativa a si ¿se va a mantener la Sección Condicionada del Fondo Regional de Cooperación Municipal en los próximos presupuestos? (Boletín Oficial de la Asamblea de Extremadura, VII Legislatura, núm. 18, 9 de octubre de 2007).
} 


\section{SITUACIÓN ACTUAL DEL RÉGIMEN LOCAL EN EXTREMADURA}

necesidad de tener una identificación propia que les distinga del Municipio matriz, como ocurre en el caso de la también «en boga», constitución de nuevas EELL Menores $^{21}$ o, como ya ha ocurrido, también, en algunos casos, la posterior conversión de la EELL Menores en Municipios o, lo que es lo mismo, la creación de nuevos Municipios ${ }^{22}$.

Pero, insistimos, lo que formulamos no deja de ser una propuesta de lege ferenda que esperamos que se convierta, al menos, en sus aspectos principales, en lege data. Lege data, que sería la Ley extremeña reguladora de las EELL que quizás, ahora sí, sea aprobada, finalmente, en 2008, si atendemos a la respuesta que dio el Consejero de Agricultura y Desarrollo Rural de la Junta de Extremadura a la pregunta formulada por un diputado del Partido Popular, en septiembre de 2007, acerca de la, que ya hemos calificado como, apremiante Ley de Entidades Locales. Efectivamente, en octubre de $2007^{23}$ - y, en gran medida, en sentido contrario, a lo que se respondió en 2005 y 2006, en relación con la misma pregunta, cuando se alegaba que no se llevaría a la Asamblea de Extremadura una Ley local autonómica hasta que el Parlamento español no reformase la ley local básica, precisamente para no aprobar una «ley coyuntural» (se decía) - , se ha venido a afirmar — como decimos, por el Consejero del ramo-, que, finalmente y, con independencia de que se apruebe o no, la reforma de la Ley local básica o se apruebe o no, la previsible reforma estatutaria, en el año 2008, si los Ayuntamientos (Municipios, debiera decir) representados en la Federación Extremeña de Municipios y Provincias lo consideran oportuno ${ }^{24}$, «se traerá, se lo aseguro» 25 .

Parece, pues, que, definitivamente, será en el año 2008, cuando se lleve a la Asamblea de Extremadura el tan demandado proyecto de Ley de EELL. Momento en el que, precisamente, se cumplen los veinticinco años de la aprobación de nuestro originario EA y, en consecuencia, de la asunción de competencias en la materia, que viene siendo objeto de nuestro interés.

De forma que a la vista de la evolución que han tenido las cosas, no podemos por menos que hacer nuestra, una expresión propia del Prof. Sosa Wagner,

\footnotetext{
21 Piénsese, al respecto, en las últimas constituciones de las EELL Menores de Tiétar, en el término municipal de Talayuela, ex Decreto 235/2005, de 25 de octubre o de Azabal, en el término municipal de Casar de Palomero, ex Decreto 267/2005, de 20 de diciembre o, en la delimitación territorial de la Entidad Local Menor de Vegaviana, en el término municipal de Moraleja, ex Decreto 32/2007, de 20 de febrero. Sin duda, hubiera resultado oportuno, en todos estos casos, haber dispuesto de la propia ley autonómica reguladora de la materia y no haber tenido que recurrir a la normativa estatal supletoria.
}

22 Piénsese, en los casos de Rosalejo y Pueblonuevo del Guadiana que, los años 1994 y 1999, respectivamente, pasaron de ser Entidades Locales Menores a ser Municipios independientes. También, para estos casos, hubiera resultado oportuno contar con nuestra propia Ley reguladora.

23 Diario de Sesiones...., cit., correspondiente a la sesión plenaria, de 11 de octubre de 2007, págs. 164-162.

24 Lo que huelga decir que lo considerarán pues, precisamente, lo vienen reivindicando desde el año 1999, a través de la resolución de la FEMPEX de 2 de diciembre de 1999.

25 Ha afirmado, literalmente (Diario de sesiones..., cit., pág. 165). 
cuando decía que «para este viaje no hubieran hecho falta estas alforjas», pues, sin duda, esperar veinticinco años para aprobar una Ley que se hubiera podido aprobar hace los mismos años, no parece ser una decisión fácil de entender. Especialmente, si como es previsible, en los próximos años se producirá tanto la modificación de la ley básica estatal, como la del Estatuto de Autonomía ${ }^{26}$.

Pero en fin, creemos que más vale tarde que nunca y, desde luego, por algo hay que empezar y ese «algo» del que es necesario que dispongamos, ya, debe contener, como mínimo, las cuestiones a las que ya hemos aludido y ello con independencia de que en un futuro, más o menos próximo, podamos contar con una nueva Ley local de regulación más amplia y, en todo caso, ajustada a las nuevas bases locales estatales.

Así pues, parece que el actual Consejero del ramo, quiere dejar de lado las anteriores excusas, a las que ya hemos considerado como completamente injustificadas y, por fin, pone fecha a la aprobación de la Ley local extremeña. Sólo nos queda por comprobar, no obstante, si 2008 es ya, la fecha definitiva o aún tendremos que asistir a algún que otro, incomprensible, aplazamiento.

\section{RECIENTES NORMAS AUTONÓMICAS SOBRE EL RÉGIMEN LOCAL Y ALGUNAS REFLEXIONES SOBRE LAS MISMAS}

Debemos comenzar destacando que las normas autonómicas de régimen local de carácter legal, tanto recientes, como más lejanas en el tiempo, son inexistentes en nuestra CA, si exceptuamos la, escasamente aplicada, Ley 5/1990, de 30 de noviembre, de relaciones entre las Diputaciones Provinciales y la CA, y que incluso las normas reglamentarias son también escasas. De estas últimas y del objeto de sus regulaciones conviene destacar, básicamente, lo siguiente:

\section{Decreto $31 / 2007$, de 20 de febrero, por el que se regula la asignación, configuración y gestión de la Sección Condicionada del Fondo Regional de Cooperación Municipal (DOE, núm. 24, de 27 de febrero de 2007)}

Se trata éste de un Decreto anual ${ }^{27}$ que, en el marco del Fondo Regional de Cooperación Municipal, condiciona el destino de una parte de dicho fondo, a

\footnotetext{
26 Seguramente, entre otras cosas, para ampliar las competencias sobre el régimen local.

27 Los anteriores se aprobaron por Decreto 38/2006, de 21 de febrero, por el que se regula la asignación, configuración y gestión de la Sección Condicionada al Empleo del Fondo Regional de Cooperación Municipal (DOE, núm. 25, de 28 de febrero de 2006) y por el Decreto 69/2005, de 15 de marzo (DOE, núm. 33, de 22 de marzo de 2005).
} 


\section{SITUACIÓN ACTUAL DEL RÉGIMEN LOCAL EN EXTREMADURA}

un objetivo propio de la política de la Junta de Extremadura, cual es la medida de fomento del empleo de desempleados. En especial, como se desprende de su art. 3, las contrataciones laborales imputables a esta sección, serán aquéllas que se desarrollen, especialmente, en servicios de interés colectivo, infraestructuras municipales, gestión administrativa, dinamización socio-cultural, conservación y mejora del medio natural, regeneración de espacios naturales y otras de similar naturaleza.

Serán beneficiarios de estas ayudas los: Ayuntamientos (Municipios, debiera decir) y las EELL Menores (art. 2).

En la medida en que se regula el procedimiento de concesión de una subvención se recogen, entre otros, los aspectos relativos a: requisitos (art. 4), solicitud de las asignaciones (art. 5), abono de las asignaciones (art. 7), incidencias que puedan suponer la extinción o la suspensión temporal de la relación laboral (art. 8), justificación final de las ayudas (art. 9), ampliación de plazos (art. 10) y compatibilidades, fiscalización y reintegro (art. 11).

Llama, sin embargo, la atención de estos Decretos anuales, y nos permite hacer una reflexión acerca de los mismos, el hecho de que dispongan, en su Exposición de Motivos, que a pesar de este condicionamiento del destino de una parte del Fondo de Cooperación Municipal, se respeta absolutamente la Autonomía Municipal; pues, a nuestro juicio, se trata de una compatibilidad sencillamente imposible, en tanto que, al menos, respecto de la materia para la que se condiciona la subvención, en modo alguno, se puede actuar autónomamente, al no permitirse la libre disposición para los EELL beneficiarios, de la cantidad económica subvencionada.

Y ello, con independencia de que cuando se habla de «subvención», deba partirse de la premisa, como recordara, en su momento, FONT I LLOVET, T., de que: «La subvención se ha convertido, hoy, en un insospechado elemento fundamental de todo el sistema de relaciones interadministrativas cuyo efecto primario, como se admite unánimemente, es el de favorecer las dinámicas centralizadoras y restringir la capacidad de libre decisión de los entes autónomos» 28. Luego, por tanto, si además de encontrarnos ante una subvención, nos encontramos ante una subvención condicionada, podemos afirmar, con rotundidad, que, al menos, en cuanto a lo que se refiere a la actividad condicionada, sencillamente, la autonomía municipal no existe.

Este tema, sin embargo, y a diferencia de otros, respecto de los que no hemos considerado, especialmente, decisiva la reforma de la Ley básica local, sí ha sido objeto de reflexión concreta y continuada, en el Libro Blanco sobre la

\footnotetext{
28 Administración Local y Comunidades Autónomas», en la obra colectiva, El futuro de las Autonomías Territoriales. Comunidades Autónomas, balance y perspectiva, Servicio de Publicaciones de la Universidad de Cantabria, Santander, 1991, pág. 186.
} 
Reforma del Gobierno Local, cuando, por ejemplo, en el Diagnóstico que formula sobre: «Unos gobiernos locales basados en el acervo europeo sobre la autonomía local», establece, en relación con lo previsto en el art. $142 \mathrm{CE}$, que aunque la libre disponibilidad de los recursos financieros, por parte de las EELL no se encuentra proclamada de forma expresa en nuestro ordenamiento jurídico interno, se percibe, en la práctica, que las administraciones supralocales utilizan la técnica de la subvención condicionada para eludir la financiación incondicionada a que las EELL tienen derecho. Disponiendo, asimismo, en relación con el análisis del «Estado de la cuestión relativo a las competencias y servicios locales», que es generalizada la demanda de mayores recursos para las Haciendas locales y la denuncia de que la efectiva participación en los tributos de las CCAA no existe o ha sido sustituida por subvenciones graciables en su concesión, condicionadas en su destino y no garantizadoras de la continuidad y regularidad de la prestación de los servicios públicos subvencionados. Ello incide de forma negativa en la suficiencia financiera de los gobiernos locales y en su potestad de planificación. Concluyendo, además, que la sustitución de la preceptiva participación en los tributos del Estado y en los de las CCAA por subvenciones a obras, servicios o actividades municipales supone una clara intromisión de dichos niveles de gobierno sobre los gobiernos locales, privándolos de su potestad decisoria fundamental, sin la que no cabe hablar de autonomía local.

Luego, por tanto, debemos subrayar «la mala prensa» que tiene el contenido del Decreto Autonómico al que nos referimos, en cuanto que supone para los EELL destinatarios, unos ingresos afectados a una finalidad predeterminada por la CA. Se trata, por tanto, ésta de una cuestión que entendemos que sí debería mirarse, cuanto antes, por parte de la $\mathrm{CA}$, por el rasero del Libro Blanco sobre la reforma del Gobierno Local, pues la institución autonómica municipal lo está demandando, con urgencia.

\section{Decreto 104/2006, de 30 de mayo, por el que se establecen las bases reguladoras para la concesión de ayudas a los grupos de acción local en la ejecución de los programas de desarrollo rural LEADER+ y PRODER II (DOE, núm. 66, de 6 de junio de 2006)}

Se trata éste de otro Decreto Autonómico, claramente «subvencionador», si bien ahora los beneficiarios no serán ninguno de los EELL existentes, sino los conocidos, en los últimos años, como Grupos de Acción Local (GAL). Y de los que, en Extremadura existen 24, 10 ubicados en la Provincia de Badajoz y 14, en la de Cáceres.

El carácter de los GAL, como se dispone en el propio Decreto, es el de ser entidades asociativas responsables de la gestión de los programas de Desarrollo rural LEADER+ y PRODER II, en la CA de Extremadura 


\section{SITUACIÓN ACTUAL DEL RÉGIMEN LOCAL EN EXTREMADURA}

A tal efecto, la finalidad básica de los GAL es la de ejecutar, en el territorio de aplicación, el correspondiente programa de desarrollo rural, informar y asesorar a la población rural de su contenido y alcance, incentivar la participación activa en el mismo, así como promover y aprobar la ejecución de proyectos en el marco del programa.

Tales Grupos carecen estatutariamente de fines de lucro y están constituidos por un conjunto equilibrado y representativo de interlocutores públicos y privados de los diferentes sectores socioeconómicos del territorio. En los órganos de decisión, los agentes económicos y las asociaciones deberán representar, como mínimo, al $50 \%$ de los agentes locales.

En la actualidad, en Extremadura, existen, como decimos, 24 GAL, de los que 10 se encargan de la gestión y ejecución del Programa Regional LEADER PLUS, durante el período 2000-2006 y, los 14 Grupos restantes se encargan de la gestión y ejecución del Programa de Desarrollo y Diversificación de las zonas rurales (PRODER II), en el mismo período de tiempo.

En el desarrollo de los correspondientes Programas, los GAL adquieren una serie de gastos derivados de su propio funcionamiento e intervención en la ejecución, considerándose necesario la concesión de unas ayudas, para dar apoyo a los mismos con el objetivo de facilitar el cumplimiento de los fines que el Grupo tiene encomendado para la ejecución de dichos programas.

Así pues, nuevamente, al tratarse éste de un Decreto «subvencionador», los aspectos que se regulan en el mismo, son los relativos a las cuestiones propias del ámbito de las subvenciones, es decir: los beneficiarios (art. 2), requisitos de los beneficiarios (art. 3), actividades y gastos subvencionables (art. 4), financiación (art. 5), cuantía (art. 6), régimen de compatibilidad (art. 7), forma y plazo de presentación de las solicitudes (art. 8), documentación (art. 9), subsanación de errores (art. 10), procedimiento de concesión de la subvención (art. 11), criterios de otorgamiento de la subvención (art. 12), órganos competentes para la ordenación e instrucción (art. 13), comisión de valoración (art. 14), obligaciones de los beneficiarios (art. 15), pago y justificación (art. 16), alteraciones de las condiciones (art. 18) y criterios de graduación de posibles incumplimientos.

Queremos destacar, no obstante, que el contenido normativo de este Decreto no aporta, en principio, ninguna cuestión significativa, en tanto que sigue los dictados propios de una norma de su carácter, pero sí que nos sirve para hacer una reflexión, respecto de lo que viene significando, en los últimos años, en el ámbito local extremeño, la cuestión del Desarrollo Rural y, en concreto, de los Grupos de Acción Local.

Efectivamente, estos Grupos se constituyeron, en nuestra Región, en el año 2003. El mismo año en el que las materias relativas a la Administración Local 
se integraron en la entonces nueva Consejería de Desarrollo Rural ${ }^{29}$, ex Decreto $82 / 2003$, de 15 de julio. Y no cabe ninguna duda de que desde la constitución de aquella Consejería y de los Grupos de Acción Local, las cuestiones relativas al denominado «desarrollo rural», se han erigido en el auténtico «ojito derecho» de la vida local extremeña.

Esta situación privilegiada se comprueba si atendemos a la normativa autonómica que se ha aprobado, al respecto, en los últimos años y que, fundamentalmente, son: el Decreto 209/2003, de 16 de diciembre, por el que se crean los Consejos Asesores Técnicos de Desarrollo Rural o el Decreto 162/2004, de 26 de octubre, de creación del Consejo Regional de Desarrollo Rural, que ha sido completado por el Decreto 73/2005, de 29 de marzo, por el que se determina a los representantes de los Grupos de Acción Local y de las Mancomunidades Integrantes del Consejo Regional de Desarrollo Rural.

Se ha querido, por tanto, en gran medida y a través de estas normas, aclarar la situación y facilitar la actuación de estas «novísimas» entidades asociativas que son los Grupos de Acción Local. Tan «novísimas» y de una vida tan corta que, en principio, en el año 2013, desaparecerán, como consecuencia de que, en esa fecha, las ayudas comunitarias que viene recibiendo nuestra CA, desde el año 2002, al ser nuestro PIB inferior al 75\% de la media de los Estados de la $\mathrm{UE}^{30}$, dejarán de producirse.

Luego, quizás, resulte comprensible que para el Ejecutivo Autonómico, venga teniendo un especial interés el desarrollo rural. Considerado, concretamente, desde el prisma de la concesión y gestión de las ayudas o fondos comunitarios que, desde el año 2002 y hasta el año 2013, nuestra CA viene recibiendo y gestionando y, para ello, esté resultando muy adecuado y necesario, el auxilio de estos Grupos. Pero no debe olvidarse, por otra parte, que la vida local en Extremadura seguirá existiendo después de 2013 y que la consistencia jurídica y, lo que es aún más importante, administrativa, de estos Grupos es más bien escasa, por no decir nula. Y, sin embargo, vienen desarrollando unas funciones que, en otros programas de tipo tradicional son, habitualmente, desarrolladas por las Administraciones Públicas.

Por ello creemos que ha llegado el momento de que - a pesar de lo dispuesto en el art. 2.2 de nuestro EA (según redacción de 1999), que prevé la posibilidad de estructurar nuestra organización territorial en Comarcas, mediante Ley, el hecho cierto de que eso no se haya producido y parece que, al menos, por el

\footnotetext{
29 Hoy, Consejería de Agricultura y Desarrollo Rural, ex Decreto del Presidente de la Junta de Extremadura $17 / 2007$, de 30 de junio.

30 Véase, al respecto la edición digital del Periódico «Hoy», de 19 de diciembre de 2006. Donde se informa que Extremadura recibirá un total de 3.401 millones de euros de fondos europeos de cohesión, en el período 2007-2013, a través de los cuales según el Ejecutivo regional se espera alcanzar la convergencia definitiva con el nivel de renta y desarrollo de España y Europa.
} 


\section{SITUACIÓN ACTUAL DEL RÉGIMEN LOCAL EN EXTREMADURA}

momento, no exista voluntad política para que esto ocurra ${ }^{31}-$, por parte del Ejecutivo Autonómico, se tienda, decididamente, a regular, fomentar y fortalecer, a las Entidades administrativas que, una vez pasado el año 2013, y si una Ley Autonómica Comarcal no lo remedia, insistimos, serán, básicamente, las «herederas» de la necesaria gestión asociada para la prestación de los servicios públicos. Y que serían las que ya se vienen denominando, en nuestra Región, «Mancomunidades Integrales ${ }^{32}$.

Recordemos, no obstante, como ya hemos destacado, que, hasta ahora, no contamos, en nuestra $\mathrm{CA}$, con ningún tipo de regulación autonómica sobre la cuestión relativa a las Mancomunidades, si dejamos a salvo los distintos Decretos autonómicos aprobados con la intención de fomentar el asociacionismo intermunicipal. Hecho éste que se viene produciendo a través de una serie de medidas, entre las que se encuentra una línea de subvenciones que se estableció en el Decreto 39/1989, de 9 de mayo y que a partir de 1998, con la aprobación del Decreto 58/1998, de 5 de mayo, se constituyó un nuevo régimen de ayudas, por el que se pretendía favorecer, especialmente, el desarrollo institucional de las Mancomunidades ya constituidas y en el que se contemplaba el concurso de las Diputaciones Provinciales, a través del mecanismo de los Convenios de Colaboración. Con este propósito y con el objetivo de potenciar la prestación de servicios municipales de forma mancomunada, fomentando la asunción de nuevos servicios por las Mancomunidades existentes, antes que la creación de otras nuevas, así como la incorporación de nuevos Municipios, a las ya constituidas, se aprobó el Decreto 56/2002, de 14 de mayo, por el que se establecía un Fondo de Cooperación para la Mancomunidades, cuyo fin principal era el de fomentar la concesión de ayudas a aquellas Mancomunidades que prestasen el mayor número de servicios obligatorios y mediante la modalidad de gestión directa, con personal propio y que cumpliesen con sus obligaciones financieras y presupuestarias, respecto de aquéllas que asumiesen servicios que pudiesen ser gestionados por otras fórmulas de asociacionismo municipal. En todo caso, esta línea de subvenciones tenía su base en el Convenio Interadministrativo de colaboración y coordinación de políticas en materia de Mancomunidades de Municipios de Extremadura, suscrito por la Consejería de Presidencia y Trabajo, la Excma. Diputación Provincial de Badajoz y la Excma. Diputación Provincial de Cáceres.

\footnotetext{
31 A pesar del confusionismo en el que, a nuestro juicio, incurre el Presidente de la Red Extremeña de Desarrollo Rural, cuando dice que: «...los programas de desarrollo europeos que se inician en 2007 instan a cada comarca a presentar de forma autónoma su propio plan de futuro y desarrollo en colaboración con los GAL distribuidos por todo el territorio regional» (Edición digital del Periódico «Hoy», de 19 de diciembre de 2006). Pero, esta afirmación nos lleva a preguntarnos: ¿a qué comarcas se está refiriendo si, jurídicamente hablando, éstas no existen en nuestra CA?

32 Véase, al respecto, por ejemplo, la Orden de la Consejera de Igualdad y Empleo, de 22 de octubre de 2007, por la que se convocan las subvenciones correspondientes al año 2007, para la contratación de Agentes de Desarrollo en Nuevas Tecnologías por las Mancomunidades Integrales de Municipios de la CA de Extremadura (DOE, núm. 124, de 25 de octubre de 2007).
} 
En el momento actual, la «política» autonómica al respecto, lo que podríamos llamar la «cuarta fase» de esta evolución se centra, en «potenciar la fusión de las Mancomunidades existentes en un mismo ámbito territorial que, además de la prestación de servicios municipales obligatorios de forma mancomunada, se conviertan en auténticas EELL prestadoras de servicios» ${ }^{33}$, como se desprende del Decreto 196/2004, de 29 de diciembre ${ }^{34}$, por el que se establece un Fondo de Cooperación para las Mancomunidades de Municipios de Extremadura.

Pero, llegados a este punto, creemos que sería oportuno fijarnos en alguna reciente regulación local autonómica sobre la materia, que también queremos destacar por su notable auge y especial significación, respecto de la EL que analizamos. Como, por ejemplo, la que se refiere a las denominadas, «Mancomunidades de Interés Comarcal» (art. 86 de la Ley Aragonesa), o por el art. 60 de la Ley Riojana de 2003, «Mancomunidades de interés comunitario». Esta última Ley, regula in extenso las características de esta nueva Institución, en sus arts. 60-63 y, por conexión, en los arts. 64-66. De la misma se ha destacado, precisamente, que los males del actual inframunicipalismo deben arreglarse con fórmulas asociativas, fórmulas que deben ser fomentadas por las CCAA pero no, como ha subrayado ARENILLA SÁEZ, M. ${ }^{35}$, sobre una completa libre elección del alcance territorial de las Mancomunidades sino sobre un mapa territorial, una zonificación, previamente diseñado por la $\mathrm{CA}^{36}$. De esta forma, como afirmaba este último autor, para el caso de Madrid, pero que nosotros entendemos perfectamente extrapolable a nuestra Región, este tipo de EELL podría erigirse en un nuevo modelo de desarrollo sostenible del territorio y de sus habitantes y, porqué no decirlo, quizás en un primer paso, de recorrido ineludible, antes de la posible y definitiva instauración del Ente Comarcal, en nuestra Región.

Es cierto que, en gran medida, provocado por las dificultades intrínsecas, especialmente, de los Municipios - como Entes Locales básicos-, para desarrollar una gestión pública, no ya eficaz, sino mínimamente posible, dado el endémico inframunicipalismo que, como ya hemos referido, también caracteriza a nuestra CA.

\footnotetext{
33 El proyecto de Decreto se presentaba, sin embargo, más pretencioso, cuando establecía que estas Mancomunidades se convertirían «en auténticas EELL no sólo prestadoras de servicios, sino en focos dinamizadores del desarrollo rural de Extremadura, a la vez que en instrumentos de cohesión y coordinación de las diferentes actuaciones y programas que inciden directamente en el desarrollo rural de nuestra Región y que son financiados por las diferentes Administraciones Públicas». Se estaba, por tanto, cuando se elaboró el Proyecto de Decreto, en la senda de apostar por una nueva forma de entender las Mancomunidades del futuro, de las que se predicaba, básicamente, su carácter de «Integrales». No obstante, la redacción definitiva del Decreto abandonó, como decimos, esta conveniente senda.

34 Modificado por el Decreto 147/2005, de 7 de junio.

35 «El Pacto Local en la Comunidad Autónoma de Madrid», en la obra colectiva, El Derecho Público de la Comunidad de Madrid, Ed. Centro de Estudios Ramón Areces, Madrid, 2.003, pág. 1139.

36 Esto lo podríamos conectar también con lo que se contiene en el Libro Blanco en relación con la necesidad de «abrir el debate sobre la procedencia de formas de asociacionismo municipal más coherentes en términos territoriales y socioeconómicos, que fortalezcan especialmente a las áreas rurales».
} 


\section{Decreto 309/2007, de 15 de octubre, por el que se regula el procedimiento de rehabilitación, modificación o adaptación de escudos, banderas y otros símbolos de las Entidades Locales de Extremadura (DOE, núm. 121, de 18 de octubre de 2007)}

La aprobación de este recientísimo Decreto autonómico viene a suponer, una vez más ${ }^{37}$, la pereza o, lo que sería peor, la fobia de la Consejería competente en materia de Administración Local, hacía la Ley, como instrumento regulador de la materia. Pues, efectivamente, esta norma reglamentaria que, por otra parte, viene a derogar a la anterior norma reguladora, cual era el Decreto $63 / 2001$, de 2 de mayo, de regulación de los símbolos, tratamientos y honores de las EELL, regula una serie de aspectos respecto de los que, actualmente, existe una especial sensibilidad, cual es el tema de los símbolos y, en especial, su significado y, por tanto, en cuanto vienen a tener un carácter identitario de la población, su respeto y protección.

Bien, pues esta norma de octubre de 2007, viene a regular la materia, de nuevo, por la vía reglamentaria, mientras que por todos es sabido que el «cachet» y las posibilidades reguladoras de un reglamento, no son los mismos que los de una ley. Ley que, por otra parte y, por la temática concreta sería, como hemos puesto de manifiesto al principio de este trabajo, claramente, la Ley de Entidades Locales y cuya aprobación, como hemos adelantado, está prevista para el año 2008.

Comprobamos, sin embargo, como a pesar de que esta norma reglamentaria autonómica $^{38}$ se ha inspirado, en gran medida, en la Ley Andaluza, 6/2003, de 9 de octubre, de Símbolos, Tratamientos y Registro de las Entidades Locales, a diferencia de ésta, que ha apostado, claramente, por elevar el rango normativo de la materia, que venía siendo también regulada por normas reglamentarias ${ }^{39}$, nuestra novísima norma autonómica ha seguido manteniendo su carácter reglamentario. Y ello tiene, entre otras cosas, consecuencias jurídicas de no poca trascendencia, como, por ejemplo, la inexistencia de un régimen propio de protección, materializado en la tipificación de infracciones y sanciones administra-

\footnotetext{
37 Y con ello concluimos este trabajo como lo empezamos, es decir, poniendo de manifiesto, nuevamente, las nefastas consecuencias derivadas de la inexistencia de una Ley local autonómica.

38 Sin entrar ahora en alguna incongruencia que hemos podido detectar, como la de mantener la competencia para la aprobación definitiva de los procedimientos en la Junta de Extremadura (tal y como de desprende del último párrafo de la Introducción del Decreto), mientras que, por el contrario, los arts. 9 y 10 del Decreto, atribuyen dicha competencia, al órgano colegiado de representación de la EL. Cuestión ésta, por otra parte, en modo alguno, baladí, pues al fin y al cabo una regulación en lugar de otra, viene a ser más respetuosa con la autonomía municipal.

39 Al estimar, como dispone, expresamente, su Exposición de Motivos, que era «necesario dotar a la citada materia de rango legal, atendida la relevancia que, para cualquier colectividad o agrupación humana, tiene su identificación corporativa, así como la circunstancia de que los símbolos, tanto estatales como autonómicos, se regulan por normativa de este rango».
} 
tivas. Catalogación de infracciones y sanciones que, como es conocido por todos los operadores jurídicos, no es posible sólo por la vía del reglamento, salvo si se tratase de un reglamento ejecutivo de una ley previa, lo que no es el caso, y sí, por la vía de la regulación legal. Como ha ocurrido en el caso de Andalucía, que ha recogido, expresamente, en el art. 21 de la Ley de 2003, un catálogo de infracciones y sanciones, en la materia. Lo que permite, además, «cerrar el círculo» de la regulación, pues no cabe ninguna duda de que una regulación que no recoja un catálogo de infracciones y sanciones, conectadas a sus posibles incumplimientos, no es una regulación completa.

Esto es, precisamente, lo que ha ocurrido con la norma reglamentaria extremeña, de octubre de 2007, que al tratarse de un mero Decreto no ha podido «cerrar el círculo» normativo y, como consecuencia de ello, su valor normativo se ve degradado.

Por ello, esperamos que, finalmente, en el año 2008, con la definitiva aprobación de la Ley Extremeña de Entidades Locales, se solventen estas últimas carencias, a las que acabamos de hacer referencia y, además de la mayoría de cuestiones que serán objeto de una primera regulación autonómica, recoja otras que vengan a aclarar, completar y elevar de rango normativo, las cuestiones relativas al régimen local que se contienen en el Decreto 309/2007 y que, irremediablemente, deberá ser derogado. Nos encontraríamos así, con un típico ejemplo de algo no querido, por la Consejería competente en la materia, como son las normas coyunturales ${ }^{40}$, y es que una Ley de 2008 , debería derogar un Decreto, de octubre de 2007.

40 Tal y como se desprende de la intervención del Consejero, en la sesión plenaria núm. 49, de 20 de octubre de 2005 (Diario de Sesiones de la Asamblea de Extremadura, VI Legislatura, núm. 55-P, pág.2756). 